Ten Years of IPS: Fracturing IR

\author{
JEF HUYSMANS \\ Queen Mary University of London \\ JoAo Pontes NogueIRA \\ Pontifical Catholic University of Rio de Janeiro
}


In the past few years the relative success of international political sociology as an intellectual project has stimulated debates about its contribution to international studies. With this issue we celebrate ten years of International Political Sociology. The journal was created in 2006, with the first issue published in 2007. It has been an intellectually fascinating ride. Since its beginnings, IPS sought to engage the "problem of the international" by questioning practices that delimit a realm called the "international" with clear boundaries as a basis for making claims about world politics (Bigo and Walker 2007a, 2007b). As such, it tried to articulate a strategy of openness and transversality that would circulate through, and connect, various intellectual terrains and could be filled in multiple ways (Lisle in this volume; Basaran et al. 2016; de Goede 2016; Guillaume and Bilgin 2016; Guzzini 2016; Leander 2016; Villumsen Berling 2015). In fact, IPS is not really an approach, let alone a school of thought, but more a signifier which connects people sharing a disposition towards traversing familiar, institutionalized repertoires of analysis; towards re-conceptualizing and displacing the questions that can be asked, the methods that can be used, the styles of arguing that are acceptable. The particular forms this disposition take depend on the lineages one draws on to do such transversal research. While this disposition has produced a rich and diverse conversation around innovative themes and strategies, we try to resist the tendency, not uncommon in intellectual movements such as IPS, to a certain normalization around empirically grounded research inspired by the shift to sociological, analytical and methodological practices (see Lisle in this volume). We therefore decided to use our introduction as a singular interference into the field rather than a state of the art of ten years of International Political Sociology. In this introduction our aim is thus not to evaluate how far 
IPS has come in creating a new and "less restrictive topology" of international relations and their boundaries. Rather, we seek to offer some insights into how this project can retain its openness, its exploration of in-betweenness, as well as its potential as a site of contestation and critique of contemporary world politics. We try to foreground the contingencies and ambivalences that characterized the critical ambition of IPS at its inception.

We choose the concept of "fracturing IR" as the instrument for this interference. It picks up a familiar theme through which the international has been critically interrogated and explores it as an IPS mode of problematizing that speaks to contemporary political concerns and opens up various conceptual and methodological challenges. It resonates with work that has been going on under headings such as “diffusion” (Strange 1996), transnationalizing (Keohane and Nye 1977), networks (Slaughter 2005), transversal practice (Bleiker 2000), global assemblages (Sassen 2006), and so on. These works are often seen as questioning the dominance of state and interstate relations but are really concerned with situations in which politics is reconfigured, not from scratch but in such ways that centering politics on states and the inter-state system, or variations of scaled up state forms of politics such as regional and global polities, misconceives where, and how, power is exercised (Walker 1993, 143).

We prefer the term "fracturing" because it resonates with the critical lineages of IPS in which we inscribe our interference, as we will develop below. The articles in this issue represent different engagements with fracturing the international. They work across various key areas and processes that remain central to the understanding of transformations of the international, including war, militarization, migration, weapons, security, and colonial legacies. They introduce a diversity of approaches, ranging from historical research and transdisciplinarity, to feminism and de-colonial thought, to a mixture of sociologies. We do not claim, however, that they cover 
the full range of work that is happening in the journal or, more generally, under the label "IPS." Yet, they do represent a quite wide range of takes on how IPS research fractures the international.

\section{Lineages of Fracturing}

One of the ways we can make sense of IPS' contribution is to look at it as a constellation of intellectual lineages formed in the context of the "critical turn" in the 1980s and 1990s and that, by the time the journal comes to life, experience a moment of intense theoretical and empirical diversification and, to a certain point, fragmentation. IPS then becomes part of moves that involved mobilizing a transdisciplinary array of analytical resources from the social sciences. In IPS these resources initially came particularly from sociology and ethnography, political theory, cultural studies, and human geography to produce studies on subjects that cut transversally into the boundaries of a statist and positivistic repertoire of North American IR. It was convergence around some major strands of critical thinking about the international that made the collective initiative of IPS possible, in particular the lineages highlighted in our discussion of fracturing as a form of problematizing the international (see below). These lineages consolidate a focus on boundary making as a dominant practice in the reproduction of the modern international, and a resistance to reading the proliferation of sites of power and struggle as part of processes manifesting some rearticulation of social (or structural) wholes. They also inspire diverse orientations regarding, on the one hand, the driving concern of post-structuralist critique - that is, the tension between temporalities and structures in a world of changing sovereign practices and statist ontologies - and, on the other, an analytical interest in actual processes and modes of "spatialization and temporalization of power" focused on agents's 
relations, positions and trajectories in specific areas and situations in a more complex network of transnational flows (Walker 1993; Bigo and Walker 2007b; Walker 2010; Bigo in this volume).

The plurality of perspectives gathered under the "umbrella" of IPS would generate inevitable and often productive tensions. For some, the umbrella should be as inclusive as possible - almost a tent-in order to renew the energies of post-positivist dispositions that had transformed the discipline, opened it to new influences and broadened the reach of its debates beyond the dominant North American academic space (Guillaume and Bilgin 2016). For others, while decentering and diversity were important, the theoretical and epistemological concerns of the previous decades had reached their limits without producing robust analytical approaches that could support sustained and novel research agendas (Kessler 2009; Guzzini 2016). For the latter, IPS demanded not just a plurality of transversal approaches but to engage more intensely with sociological research programs that resisted reification in spatio-temporal frameworks of systemic theories, drawing, instead, transversal lines contingent on knowledges and relations that couldn't be reduced to the ontological terrain of the state (Bigo 2016). In the journal, Bourdieu, Luhmann, and sociological readings of Foucault's work were initially some of the more outspoken sources people drew on to deliver such research agendas. More recently, actornetwork theory and more broadly Science and Technology Studies have started playing a similar role. Both orientations are constitutive of how IPS engages the lineage of the "critical turn" in Anglo-American IR in the 1980s and 1990s. They create a tension that allows IPS to engage the critical lineages of the 1980s and 1990s in dynamic and creative ways. As an intellectual and institutional sphere it addresses a need for both transversal sociological theorizing and empirical analysis and an engagement with the limits of such sociological programs by drawing on different disciplinary resources, such as cultural studies, feminism or aesthetics. For example, 
Jarius Grove's contribution to this issue draws on actor-network theory, but the main intellectual lineage is an ecological philosophy drawing on Whitehead and object philosophy. It leads to an analysis that works through juxtaposing and collage rather than a more systematic deployment of sociological concepts, procedures, and observations. It is a way of working by which he seeks to understand war by placing it in a broad ecological interconnectedness of things, humans and various spheres of life rather than by focusing on the specificity of transnational fields of professional elites or case studies of military technology and what they tell us about changes in war. This approach is controversial and will raise questions about its value, but it represents work that seeks to engage in distinct and less sociological ways the contemporary dissolution of the line between everyday, banal life and "the battlefield" and "war-fighting strategies" in the politics of war. It incorporates the experimental lineage that was central to how "the critical turn" deconstructed familiar repertoires of IR knowledge and method (e.g. Der Derian and Shapiro 1989; Enloe 1989; Sylvester 1994; Weldes et al. 1999).

As we can see in the early years of this journal, these two intellectual positions generated a lively debate and scholarly production around the multiple ways borders work and how the innovations in conceptual and analytical approaches-enriched by an open engagement with transdisciplinarity —allowed for research on airports, camps, surveillance regimes, technologies of government, violence, migration, citizenship, law, finance, and many other topics without falling into epistemological dead-ends or into the muddled narratives of post-sovereignty.

As we look to its trajectory, we are convinced that IPS is fortunate in resisting definitions, research programs or efforts to turn it into a "school" of thought. It works, rather, as a signifier, creating conversations and lines or lineages of inquiry. As Debbie Lisle aptly states in her contribution, we stand in a "difficult and demanding terrain of inquiry that scholars must 
fight hard to keep open, pluralistic and hospitable to new ideas" (Lisle in this volume). As we start from a position that realizes the ever-shifting terrain in which IPS problematiques unfold, we try to formulate the notion of "lineages of fracturing" in an effort to highlight what IPS does, and stands for, in its different articulations.

As we mentioned before, we use the term fracturing because it resonates with the critical disposition in which we inscribe our reading of its lineages and its overall contribution to international studies. Also, we want to distinguish this reading from more familiar notions such as "fragmenting" which have been frequently used by different theoretical perspectives with various meanings, often associated with problems of order and/or integration of the system of states. In fact, it is fair to say that since its inception IR has been concerned with the creation of political order in a world fragmented into different kinds of units - mostly national and territorial states. More recently, especially after the end of the Cold War and the changes that took place in its wake, the problem of order and its fragmentation/integration dualist dynamics acquired considerable relevance in most narratives about world politics.

The lineages of IPS we discuss here have engaged with a range of critical views on the problem of the decentering of power away from the state, such as early work on transnational relations, the role of non-state actors, the distribution of agency in networks, the growing complexity of regimes and their normative arrangements in areas such as finance, technology, law, and so forth. These narratives, which include contributions as diverse as Keohane and Nye (1977), Strange (1996), Ruggie (1993), Kratochwil (1989), Bleiker (2000), Slaughter (2005), Sassen (2006), and Agnew (2009), among others, respond in different ways to often contained suspicions about the inadequacy of well-established assumptions about the location of politics. As the debates of the 1980s and 1990s came to a close, rationalist and constructivist approaches 
articulated a synthesis that reconciled state-centrism with conventional analyses of diffusion of power and fragmentation of authority, producing a new and still dominant orthodoxy in North American IR. In conditions of increasingly complex interdependence, states found more incentive to create and participate in institutions of global governance which displayed capacities to generate quasi-legal rules and obligations. Institutionalists incorporated social constructivism to account for states' compliance with, and diffusion of, norms, combining interest-based and identity-driven explanations for state dispositions to share authority and sovereignty. Institutions operated in a densely norm populated system that functioned as bridges, connecting domestic and international political actors and processes (Wendt 1999; Barnett and Finemore 2004; Katzenstein, Keohane, Krasner, 1998).

While the critical turn had been crucial in IR's shift towards "the social" and in opening spaces for a range of modes of theorizing until then marginalized from the field, we could argue that IPS emerges, in a sense, in the context of a strategic defeat of post-structuralism's sustained efforts to unhinge the ontological and epistemological foundations of disciplinary IR. Ole Waever marked this defeat as the fourth debate in which IR recreated a middle ground around moderate social constructivism and neo-institutionalist approaches that neutralized the sharp edges of both the more radical rationalist research programs and post-structural experimenting (Wæver 1997). As a "countermove" that overcame traditional dualisms of positivist social sciences, IPS took as its "starting point ... a relational and processual ontology ... with a specific take on the social [that] qualified a (pure?) discourse-oriented analysis" and was much more open to an empirical disposition (Guzzini 2016). This relative distancing from deconstruction can also be found in certain critics' claims that it reaffirms the binaries it sets out to destabilize and "inevitably brings us back to the original foundations of authority" (Bartelson 2015). In the 
end, there was a sense that a certain obsession with sovereignty kept bringing us back to the problematization of the state and its morphings in order to understand world politics, somehow reifying, if not the state, the problem itself, in detriment to an attention to changes and the practices that produced them (hence Campbell's call to go beyond the sovereignty problematique. De Goede 2016).

So, what does "fracturing" contribute to these concerns about power, authority and politics not really being where they are supposed to be? What does it offer as an alternative view of the decentering of the state and the diffusion of social practices of authority? Its distinctness follows from two interconnected lineages that define IPS as a particular mode of problematizing. These lineages are: a) the critical interrogation of familiar repertoires of analysis in IR in the 1980s and 1990s by displacing the focus from studying politics across instituted boundaries and limits to researching the exercise of power that takes place in the practice of boundary making and defining limits; and b) post-structural modes of problematizing that challenge structuralist social sciences that read the political significance of practices as manifestations or, more accurately, enactments of totalities, but without falling back on individualist or agency focused analyses.

\section{The Question of Limits}

Perhaps no other critical interrogation of dominant modes of interpretation of the international has been more influential in the formative process of IPS than the question of limits. Most of the crucial debates of the 1980s and 1990s are framed by it, in one way or the other. To be sure, the question bears the mark of Foucault's "analytic of finitude," developed in 
his critique of structuralism and phenomenology in the Order of Things. In this, he reads Kant's reflection on the irruption of modernity as the idea that "the limits of knowledge provide a positive foundation for the possibility of knowing" (Foucault 2002, 343). Walker aptly explored the antinomy which makes finitude both the positive limitation and the foundation (possibility) of truth claims in the disciplinary practices of the social sciences when he states that, "Theories of international relations can ... be read as a primary expression of the limits of modern politics" (Walker 1995, 32). In fact, his major contribution to the articulation of a critical position in that particular context was to take international theories' claims about the limits of the political as a condition of possibility of its knowledge about international relations (see also Ashley, 1987). Moreover, the limitations of politics outside the boundaries of the state constituted the limits of transformative projects within national communities. Communities can create change, but only up to the point they run into structural constraints of the international system, whether in the form of demands for security in conditions of international anarchy or dependencies upon other states and international institutions for sustaining economic, social, cultural and political reforms. In fact, any change is interpreted within the framework of modernity, in other words as a transcendence of limits that insist on staying exactly where they are. For example, claims about global governance ending up reiterating blue-prints of scaled-up, state-like polities or structural realist reduction of change to temporal unsettling that will end up sooner rather than later in familiar structurations of states and the international. Such claims remained circumscribed in the spatial imaginary of the territorial boundaries of sovereign states, only to reproduce the ambivalent move of transcending boundaries in order to reaffirm their constitutive role in reproducing the sovereign state. The debates about uni-, bi- and multipolarity, the peace dividend, global civil society and global governance following the end of the Cold War, offer a 
microcosm of such moves of controlling change by enacting it through and within the limits of modern state-based categories of politics. Hence, making the question of limits and how they condition international practice and knowledge a central focus of analysis and concern questioned the very foundations of IR's claim of change in world politics given structural realism's and, more broadly, IR's inability to relax its statist assumptions in order to "bridge" the gap between "external and internal" and account for how more intense interactions across borders in complex interdependencies reconfigure politics (Keohane 2002). The problematic character of change was also present in "progressive," neo-Marxian visions of politics; here, the displacement of the boundaries between national/transnational, or global/local was interpreted as new conditions for social movements, non-state actors and even changing state-forms (or postnational political communities) to enact counter-hegemonic strategies and practices of resistance in a "global civil society." This literature interpreted the transformations in global capitalism (or globalization) as potential conditions to overcome the limits to emancipation imposed by national states. This brand of left cosmopolitanism ranged from the modified structuralism of Gramscians, such as Cox and Gill, to Habermasians, such as Linklater (Gill 1993, 2003; Cox 1996; Linklater 1998).

We can argue then that IPS emerges as an instance of a distinct, fracturing problematization of the question of boundaries and limits or, to put it differently, of the challenge to the spatial containment of temporality and contingency in international relations. It takes seriously the idea of making limits and boundaries themselves the object of research by seeking to invent ways of understanding the practices that take place upon the boundaries and that reconfigure limits. It does this in ways that seek to understand configurations of politics after the international and global but before the world, that is, political life that does "not quite work as 
the categories of modern political analysis suggest they ought to work" (Walker 2010, 23) and that takes as its default position that "the entire world is forever beyond reach" (Walker 2010, 22). This lineage of IPS challenges both disciplinary pretensions to establish clear boundaries for the production of knowledge and the legitimation of critique; as well as its delimitations of the boundaries of the international, either in narratives of global governance or in the more particularistic affirmation of (constructed) state identities. The questioning of limits runs, precisely, against the reinstatement of a modernizing vision of the international, now moderated and civilized by more domesticated (or well-governed, if we use neoliberal jargon) states, and more robust institutions of global governance. This is the process Bigo and Walker refer to as "getting rid" of the problem of the international by means of the constant redrawing of familiar, even if modified, lines of demarcation of the political and the non-political, the local and the global, the public and the private, and so on (Bigo and Walker 2007b, 730). In our understanding, the contributions to this issue are each part of this lineage, questioning and engaging limits and boundaries in ways that try to understand political lives that fracture familiar lines of demarcation between disciplines (Lisle in this issue), global and local (Johnson in this issue; Abrahamsen and Williams 2009), modern and non-modern (Rojas in this issue), the banal and extraordinary (Grove and Enloe in this issue), today and yesterday (Bartelson in this issue), center and periphery (Bigo in this issue).

This lineage of fracturing thus not only refrains from looking at boundaries as devices with which processes of fragmentation and integration are managed, or as markers crossed by transnational flows. Indeed, IPS proceeds to engage in the analysis of the practices of boundary making and in the critique of their effects as sites of power, surveillance, control, exception and exclusion (Basaran et al. 2016), or as places of contestation of the very inside/outside divide they 
produce, which require "diverse and multiple logics and practices of inside/outside in order to highlight... what is enabled, legitimized and concealed by border politics" (Vaughan-Williams 2008, 336; Johnson and Lisle in this volume).

\section{Post-structuralist Lineage as Meaning Literally "After Structuralism"}

The second lineage we bring into our effort to articulate fracturing as a practice of problematization of the international refers to post-structuralism's critique of systems and structures understood as social wholes, or totalities. The centrality of the post-structuralist lineage in IPS highlights its connection to the critique and reconfiguration of structuralism in the social sciences debates of the 1960s and 1970s (Foucault, Deleuze, Derrida and so forth) and in the deconstruction of structural realism in IR (Ashley 1984; Walker 1993). We read the poststructuralist lineage of IPS as literally "after structuralism," recognizing the continuing influence of structuralism in international political sociology and the interesting ways in which it was rearticulated in multiple transdisciplinary strategies that include sociologies of practice, enthographies of everyday life, political philosophies of immanence and contingency, new materialisms, and so forth. In other words, the critique of structuralism still informs several ontological moves in IPS aimed at dealing with the problem of change in modern spatiotemporal configurations of the social, the political and the international. It implies that, as with the problem of limits, constraints on contingency, practice, and temporality cannot be dealt with either by reinstating dualities of agency and structure through new subjectivist epistemologies, objectivist ontologies of the social that yield actor driven analysis or by dispensing with structure altogether. The post-structuralist lineage we think of more specifically tries to capture how 
structuralism and after contributes to rethinking relationalities of practice and power in modes of immanent connections and becoming.

In his now classic 1984 essay against neorealism, Richard Ashley takes as his starting point E.P. Thompson's critique of Althusser's structuralism: “a self-consciously scientific perspective ... that had superimposed a positivistic understanding of science upon Marx ... ignored history [and] abolished the role of practice in ... making social structures. It had produced an ahistorical and depoliticized understanding of politics" (Ashley 1984, 226, 255). Ashley would then proceed to analyze neorealism as the reproduction, in North American IR, of the same errors of continental Marxism; as the analogous ideological movement of a "totalitarian project of global proportions: the rationalization of global politics" (Ashley 1984, 228). In a way it is unfortunate that one of the most influential texts of the critical turn in IR produced such a superimposition of a complex —even if somewhat impoverishing - moment in the trajectory of Western Marxism to the vagaries of North American political science. This strange move was to provide the basis for a critique of the "neorealist movement as a whole," yet in the end resulted in a critique of structuralism as a whole - of a certain interpretation of structuralism that is, one overdetermined by the debate in American IR and by the well-known antipathies of British Marxists towards continental philosophy. Ashley would later reposition himself in a more thoroughly poststructuralist critique of the anarchy problematique, but did not follow through on the critique of structuralism and the engagement with its limits and its critical lineage in the broader debates about structuralism within Marxism and continental philosophy more generally. The focus turned to a repositioning of re-inscribed classical realism and interdependency theories - instead of neorealism — as better analytical tools for understanding international politics (Ashley 1987). 
Walker worked in the same moment and interrogated a similar problematique, but engaged the philosophical debates more consistently and, in particular, the question of change and temporality in relation to structuralism. In his critique of American IR, Walker adopts the general position that structuralism is realism's response to the dilemmas of change (as well as a critique of historicism), a solution that privileges a spatial/static/statist conception of politics over temporality and history. However, while Walker agrees that statism, combined with functionalist and positivist epistemologies, stabilizes the indeterminations of political reason that Waltz and Keohane find in their classical formulation, he is less sanguine that stucturalism, as Ashley so clearly asserts, stabilizes the boundaries of the political, domesticating time inside them as it relegates it to repetition outside. Moreover, Walker sees the move to reconcile methodological individualism with the holism of a system that operates simply as a structure of differentiation (governed by the logic of anarchy) as deeply problematic. Neorealism's scientific/functionalist model accounts for structural causes and effects that allow for an empirically verifiable representation of a self-contained and cohesive system characterized by the continuity of its structure as well as by the functional lack of differentiation of its constituent units - states. While for Ashley (and Ruggie) neorealism is flawed due to the contradiction in its generative logic (individualist/atomist) and its ontological assumption, holism (the structure precedes its units), Walker is more interested in how this particular solution of the relation between structure and history expresses the unsettled relation between difference and identity in realism as a political philosophical tradition of which neorealism is just one more instantiation (Walker, 1993: 104-124).

The interesting point in Walker's critique, for the purposes of our discussion of the lineage of post-structuralism, is his reading of structuralism as a problematization of difference 
by means of a spatialization of politics which only holds through sovereign practices. In other words, sovereignty holds the state and the system of states together by "restructuring political space" and constitutes the international as the realm of difference mediated by the sovereign state - the sovereign boundary making subject and the vehicle for the reproduction of a universal reconciled to its perennial differences. We are soon reminded of the problem of limits discussed in the previous section. But, more interestingly, we connect to it the insight that their "ontological powers of determination" are only made possible by the "radical discontinuity" inherent in structuralism's response to the relation between history and structure, the topology of which is precisely the - temporal and spatial-line between the eternalization and the abolition of difference that characterizes international theories. This tension is absent in Ashley's "conventional" critique of structuralism (Walker, 1993:115), which focuses on normative and logical contradictions in an already dominant form of structural realism. Even though in Walker we also find an attraction to political realism's emphasis on practices (and change), as well as to an "ambivalent" historicism, as necessary to affirm difference; his reading of structuralism looks much more at how it opens questions about the considerable difficulties of understanding how structures are produced politically without falling into familiar dualisms of agency and structure. His answer draws on post-structuralist foregrounding of relationalities to problematize the distinction between whole and parts, with all its implications for the place of the subject and the possibility of critique (Walker, 1995:95). In the end, Walker finds himself in a not too distant place from Althusser, both rejecting idealist (historicist or phenomenologist) unifying principles that can overcome fragmentation and their associated teleologies, as well as the recognition that the possibility of critique lies in the openness towards "the event, the as-yet unimaginable, and also all living practice, politics included (Althusser 2006, 264). This is not so surprising given 
that Althusserians and post-structuralists, although from different and at times openly conflicting positions, were engaging the limits of structuralism from within a structuralist lineage, being careful to avoid agency driven alternatives. The concept of "fracturing" aims to draw attention precisely to how IPS has strong connections to these re-configurations of relationality after structuralism that emerge from working through and engaging the limits of various modes of structuralism.

The lineages of post-structuralism in IPS expose the limits of its critique of sovereignty and the modern international imagined as a social whole, as a nostalgic conception of a political community that, by means of an alternative political imagination and radical practices, could reconstitute itself by destabilizing (or decentering) its boundaries. However, IPS is also defined by the structuralism inherent in the post-structuralist critique, which was systematically deniedor sublimated - in the theory wars of the 1980s. ${ }^{1}$ Put differently, if post-structuralism both "inherits and combats structuralism" (Choat 2010, 14) we argue that there is much of this ambivalence informing IPS scholarship and also that such ambivalence is at work in our approach to fracturing as a form of problematization and critique. In this sense, we distance ourselves from a critique of structuralism perhaps excessively informed by the assault on IR orthodoxy which emphasized the static and essentializing aspects of structure, as well as its aversion to change. Alternatively, we argue that structuralism and after, as a lineage of IPS, recovers the refusal of grand narratives, the search for origins, the temptations of historicism, the centrality of power and the power of the center while retaining a focus on the conditions of possibility of knowledge, practice, and relations. We can find instances of such lineage in

\footnotetext{
${ }^{1}$ The turn to Bourdieu in IPS is one of the clearest expressions of this. One of the challenges for IPS, however, is that the debates on structuralism remain defining for IPS and that ignoring them risks returns to quite totalizing readings of politics, for example to returns to theological conceptions of the political. We therefore think that the post of structuralism remains and has to remain a key defining set of resources for IPS.
} 
several strands of IPS research in the past ten years, such as the sensitivity to the event, an attention to historicizing and analyzing the social in a non-teleological way, drawing in particular on Bourdieu and some readings of Luhmann. Also Foucauldian analyses of the circulation of power through dispersed or networked sets of institutions which only contingently acquire cohesiveness in specific regimes of knowledge and practices of government share this lineage. (Hindess 2005). Feminist interrogations of the differentiations between the private and public, the trivial and the extraordinary, and the banal conditions of possibility of so called high-politics are another example as are analyses drawing on Latourian and Deleuzian conceptions of relationality. Taking these together we can see how the search for discontinuities and the rejection of totalities and general principles in favor of multiplicities (in time and space) is a defining feature of significant work in IPS and has been clearly present in several contributions to this journal (e.g. Best 2008; Soreanu 2010; Kopper 2012; Squire and Darling 2013; Ní Mhurchú 2015).

However, we can find tensions in this lineage, perhaps the most relevant of which lies in the familiar move from "international relations" to "world politics." In the context of the critical turn the move expressed the anti-state-centric disposition of the time and an attempt to submit the principle of state sovereignty — with all its ontological claims - to destabilizing scrutiny. It also expressed the explicit dissatisfaction with the spatial rigidities of IR, expressed in the structural rendering of the international system as a politically barren totality. While for some, world politics (as well as other, local politics) "was rendered impossible" by the centrality of statist politics as a spatial politics (Walker 1995), many saw the positing of world politics as an opening to non-state actors, transversal flows, networks, assemblages, decentered regimes of government and/or governance, and so forth (Albert 2007; Abrahamsen 2009; Thomas 2009; 
Bartelson 2010; Kessler 2012; Bigo, this issue). Different formulations of the problem emerged in analyses of world society, globality, governmentality, global governance, governmentality, among others, mostly inspired by sociological approaches, particularly the practice turn and more empirically oriented and methodologically pragmatic analysis of social processes; as well as by Foucault's later lectures on government (Tosa 2009; Kurki 2011; D'Aoust 2013). To be sure, these contributions were mostly critical of globalization theories and the move to the global that characterized them and posited globality as a single social space (Huysmans et al. 2009). However, the notion of the "global" proliferated in the pages of IPS, even though a "social ontology of globality remained undetermined" (Bartelson 2010). While most of these approaches avoid the discussion of an ontology of the social, they still work with it as a background assumption for their analysis. Indeed, it would seem that the condition to speak about the political without falling into statist or territorial traps is to posit the global as "world," that is the complex terrain in which transnational and transversal intersections take place. The problem becomes how to trace or link the articulation of practices to this more fragile and contingent space without reproducing globality as an expression of the international or as a social whole. The specter of structuralism looms large in spatial representations of a global space always at risk of closure. The fracturing methods and concepts that IPS has introduced are those that seek to negotiate tensions between the precariousness of relations and their closure not only spatially, but also temporally, in its conceptions of worlds, globality and transversality . These are tensions that have their roots in the problem of structure after structuralism, which in IR are expressed through the critique of the international and globalization. 


\section{Fracturing: An IPS Mode of Problematizing}

In this section we introduce two conceptual vehicles for fracturing IR that are inscribed in the IPS lineages discussed above: connecting and becoming. They facilitate deconstructing familiar distinctions between past and present, local and global, and identity and difference by means of developing associative modes of research for understanding contemporary conditions of power relations.

\section{Fracturing as Connecting}

The starting point for this conception of IPS is to move from "units" to the "enactment of connections"; a move others have referred to as foregrounding process approaches (Jackson and Nexon 1999; Guillaume 2007, 2009; Kessler 2009; Guzzini 2016). IR tends to understand society, state, the international and the global as units or, more accurately, "wholes" that exist simultaneously as acting entities and structural givens that explain what is taking place within them. IPS challenges such interpretations by fracturing given "entities" into the practices through which they are enacted - that is, simultaneously created, reiterated and changed (Guillaume and Bilgin 2016). In other words, it approaches societies, states, the international, and the global from the point of view of how they are continuously in a process of being made and remade (Simmel 1971; Macherey 2009, 133-135).

Fracturing in this sense is not fragmenting. It does not read histories and situations as dialectics of fragmentation of units into smaller ones and integration of smaller units into bigger ones. Instead it focuses on practices of connecting. Such a focus on the importance of "connecting" is not simply an analytical move; it plays also in political debates such as whether 
citizenship rights should derive from nationality, from being engaged in transactions in a specific territory, or from transversal transactions that connect people, irrespective of boundaries between political communities (Isin and Nielsen 2008; Andrijasevic et al. 2012; Aradau et al. 2010; Weber 2010; Squire 2011; Chauvin and Garcés-Mascareñas 2012; Shindo 2012; D'Aoust 2013; Barabantseva 2015; Isin and Ruppert 2015). Jarius Grove's and Cynthia Enloe's contributions to this issue express how fracturing as connecting also translates into a distinct method of associative writing. Their analyses do not fragment but bring in relation various bits of instances, theories and philosophies, and political engagements to bring out how power is dispersed and how warring and militarizing modes of connecting are enacted.

Connecting introduces a recognition that it is futile or misguided to read patterns as total, organized wholes. It locates IPS in lineages of thought and methods of work that favor attentiveness to singularities rather than generalities and grand narratives (Rabinow 2003, 35). However, foregrounding connecting poses a significant challenge to the widespread use of ideal type reasoning to engage singularities ${ }^{2}$ (Bhambra 2014). Although Weber's use of ideal types allows for more variety (Rabinow 2003, 31-43), ideal typical heuristics mostly focus on identifying distinct practices, cultures, or forms of life rather than on the practices and histories that work across them and that when connected challenge the understanding that the type produces.

To understand events in terms of ideal types is to argue that they are knowable in terms of processes represented as internal to the type. Connected sociologies, in contrast, seek to reconstruct theoretical categories-their relations and objects - to create new understandings that incorporate and transform previous ones. (Bhambra 2014, 4)

\footnotetext{
${ }^{2}$ We draw here in the first instance on Bhambra's work (2014). Her reading of ideal type challenges the way they have been used in comparative sociology. As a result, it differs from more positive readings of Weber's ideal types, such as Rabinow's (2003), which understands “ideal types as heterogenous assemblage brought into a form" and for whom ideal types are a method that foregrounds singularities.
} 
Even when work in IR and sociology does not explicitly refer to "ideal types," they remain very present, ranging from classifying widening security practices as "sectors," to identifying "native cultures" and "modern cultures," to reifying "the international" and "the global" as discrete entities that are defined by their internal workings. Ideal types diversify but they do not fracture situations in the way we understand it. To differentiate her approach from ideal typical methods, Bhambra introduced the concept of "reconstruction." Research reconstructs knowledge by seeing a plurality of possible connections and selecting some of those connections, including explicitly less familiar ones, to create opportunities to challenge instituted knowledge and explanations. In other words, reconstructing through connecting focuses on the creative work that happens through relating issues. Such reconstructions are thus not about multiplying the number of ideal types, for example introducing coloniality into sociological analysis by multiplying different cultural types (Bhambra 2014, 146). The issue is rather one of displacing the familiar as it is rendered in, and through, the types. Rojas's is one of the contributions to this issue that explicitly engages this mode of connecting. She revisits the debates in post-colonial and decolonial studies on how to engage the dominance of modern epistemologies developed in colonial powers to develop a pluriversal approach to global and international politics. Similar to Bhambra, she argues for connecting knowledges and situations that fall outside of IR to instituted Western cannons. The aim is to insert a set of historical and actual relations that disrupt familiar repertoires of understanding in engaging issues like globalization, multi-culturalism, European integration, migration, environmental politics, and so on (also Seth 2013; Shilliam 2015). Lisle's call for transdisciplinary connecting in this issue and her notion of the "happy wreck" presents a similar understanding of IPS, but by engaging the 
limits of sociology within a wider debate about the value of working transversally across disciplines (also Barry and Borne 2013).

In doing so, connecting also breaks away from the universalizing normative effect often implied in ideal typical reasoning (Bhambra 2014, 147). The latter assumes that the categories inscribed into the ideal type have universal validity, not in the sense that they cover all there is to know about the world but rather that they can be applied everywhere. The category of "the state" functions like that in IR, identifying different types of states according to its capacities to perform the functions of a general, universal form of stateness. The multiple indexes of classification of more or less functional states inhabiting peaceful or conflictual zones in the post-Cold War world reestablishes patterns of fragmentation and integration familiar to the modernizing narratives of IR.

There are several ways in which this mode of fracturing generalities into singularities through connecting is exercised. Bhambra's and Rojas' reconstructive reading of historical connections is one such mode. Assembling heterogeneous lineages through taking particular media, ranging from body scanners (Bellanova and Fuster 2013) and Key Performance Indicators (Schouten 2014, 31-32), to YouTube (Austin 2016), to improvised explosive devices (Grove in this volume), is another (also IPS Forum, Best and Walters 2013). Following distributions of capitals and their temporal homologies with the distribution of dispositions is another (Cohen 2010; Bigo 2011; Bigo and Madsen 2011; Dezalay and Garth 2011; Leander 2011; Bigo in this issue). Working immanent relations between resistance and domination, and between contradictory modes of practice, is yet another (Budz 2009; Dunn Cavelty and Jaeger 2015; Ryan 2015; Davies 2016). 
Drawing on this concept of connecting introduces a distinct mode of doing IPS. As set out in the previous section, from its inception International Political Sociology has been interested in boundary work and life that takes place on the line rather than simply across it. Not surprisingly, the journal has attracted a lot of work on the excluding effects of security practices, sociologies of borders and bordering practices, and migration which are key areas of political and governmental line drawing. Yet, these areas are also sites that connect histories of migrants with institutionally embedded histories or that shape "border life" as distinct forms of relating that are formed and reformed in the many encounters taking place between immigrants, those facilitating mobility, and border guards and technologies, for example (e.g. Papadopoulos et al., 2008; Vaughan-Williams 2008; Andrijasevic 2010; D'Aoust 2013; Huysmans and Guillaume 2013; Scheel 2013; Barabantseva 2015). Heather Johnson's contribution to this issue proposes to read narratives of immigrants as a method to not only question the distinction between local and global as levels of analysis but also to get a sense of the many everyday encounters through which mobility is constituted. They do involve discriminations, exclusions and violence, but they also express multiple relations that are taking place which shape what "being mobile as immigrant" means as modes of being.

"Connecting" does not ignore the importance of, and the exclusions and violences created by, line drawing and boundary work. Yet, it seeks to add to this lineage of "critique" a mode of analysis that looks at the sociative work done in exchanges, reciprocities, transactions, encounters and so on. Instead of fracturing IR first and all by looking at multiple separations that are enacted and multiplied, it re-inscribes this lineage of critique with a mode of fracturing IR and structural wholes by means of associative research that foregrounds the significance of the work done by the little things of life that connect people and things and that are mostly ignored 
by macro-sociological analyses. Borrowing a phrasing we first encountered in Bayart's work (Bayart et al. 2008, 11), connecting introduces a research disposition that recognizes that little nothings do the immense work of simultaneously making and unmaking macro-sociological entities. They are not a micro window that offers us glimpses of the macro structures. The little nothings actually do the work of associating people, things, and situations in ways that simultaneously shape, reshape and bring into being social forms such as war, militarization, and global governance. For example, the flick of the skirt, in Cynthia Enloe's contribution, does not receive its meaning from acting out a structure of militarizing but rather militarism takes shape by how the flicks of the skirt connect people, institutional life worlds, and militarizing practices. Obviously, this interest in how to take seriously the work that little practices and things do places IPS strongly within feminist lineages, but not only. In addition, work-which has been quite present in the journal-that revisits literatures on "the everyday," draws on actor-network and posthumanist theories, or explores the (international) political significance of art and popular culture, among others, represents this attentiveness to understanding the power of what in IR is often treated as trivial or insignificant.

What we are aiming to show by drawing attention to "little nothings" is not that IPS favors micro over macro but rather that it favors an interest in the development of concepts and methods that have no need of the categories of micro and macro. It is a care for inventing modes of analysis that introduce distinct ways of working with a flat ontology (see also Grove in this issue) that allows for understanding structural properties of situations and phenomena as enacted rather than given. They are simultaneously brought into being, reiterated and changed, without a need to build into the analysis hierarchies between micro and macro or center and periphery. For example, Marston, Jones III, and Woodward (2005) develop such an approach in their critique of 
the use of scales in human geography. They argue for "a focus on localized and non-localized emergent events of differential relations actualized as temporary—often mobile—'sites' in which the 'social' unfolds" (Marston et al. 2005, 423). Such arguments alone do not immediately show us what an analysis of a phenomenon would look like but it does set out a distinct approach that organizes research around sites. It treats sites not as macro or micro but as a concept/method of doing a mode of connecting in which what otherwise would be named micro, such as the flick of the skirt, and macro, such as militarizing institutions, turn into simply situated practices and things in which phenomena such as militarization unfold or, in our terminology, are enacted. Leonie Ansems de Vries explores similar fracturing moves in her work on the concept of "the milieu" (Ansems de Vries 2015). In this issue, Cynthia Enloe's, Jarius Grove's, and Heather Johnson's contributions represent different takes, mobilizing distinct lineages and concepts, on how to do a connective analysis that seeks to overcome the distinction between micro and macro, so as to acquire more adequate and distinct understandings of contemporary phenomena and challenges.

\section{Fracturing as Becoming}

In the previous section we developed fracturing as an analysis of connecting. In this section, we focus on how this mode of IPS fractures temporality by taking time as becoming (Grosz 1999, 3). Fracturing temporality addresses two challenges in particular: first, avoiding conceptualizations of time that oscillate continuity and change or old and new; and, second, introducing the co-existence of multiple temporalities without juxtaposing historical time and lived or phenomenological time (Hutchings 2008; Shapiro 2016, 15). 
"What is new?" is a standard question anyone presenting a paper is asked once in a while. It is an easy question to ask; it does not require much from the discussant because it is usually fairly easy to find a connection to some continuity with the past. Yet, the question is common also because the "new" that is claimed in social sciences often takes the form of epochal change, significant crisis moments that break continuity, and so on. History is carved into moments of big changes, when the old world no longer works and the new is not yet born. The old then becomes a period of continuity and the new is constructed as a new continuity that we need to understand, analyze, discover. The "what is new?" then, has both a methodological function of asking for refined articulations of what characterizes the current time compared to the previous time and a critical function of challenging claims of change by implying long term continuities. There are plenty of issues here, but the main point is that time is understood as either a succession of continuities broken by moments of change or a single continuity with different historical times as variations of it. Time is either broken or structuralized. (Historical time is also mainly singular in both these conceptions but we will come back to this below).

The version of IPS we are introducing seeks to disrupt such oscillations between time as continuity and time as structural change by making continuity and change, old and new, immanent to the present and by inscribing an orientation to the future that focuses neither on the future as distancing from the past and present nor as continuity of what already is. Instead, futures are possibilities emerging from "little lines of mutation" (Deleuze 1979, x). Possibilities, here, are not projects that allow us to construct the future through their realization, through implementing a vision of the future. Instead they are minor histories and events that actualize both the past and future in ways that unsettle the continuities and identities through which we 
like to enact the world (Rajchman 1999, 48; Collier and Ong 2005, 15). Time is "becoming" rather than "break," "identity" or "continuity."

It means that to understand the present enactments of, for example, borders one introduces various mutations in technologies of surveillance, international police cooperation, organization of corporations and markets. They intertwine, each simultaneously working and reworking old practices which enact a "contour" or "surface" that is distinct and singular, that is irreducible to the old or past but is not really a paradigmatic break; it is something that is both old and new. Rabinow's anthropology of the contemporary develops such an approach to time in anthropology, for example (Rabinow 2008). In "the contemporary," present and futures are not a reproduction of the past but mark distinct intertwinings of old and new. For example, the notion of "pre-emptive security" seeks to identify a change in contemporary security towards anticipatory security practice (e.g. Amoore and de Goede 2008; Aradau and van Munster 2008; de Goede 2012; Amoore 2013). By being hooked into the 9/11 moment it sometimes feels like it is seen as a new paradigm of security practice. However, it is connected to various "histories" or lines that have no immediate connection with the $9 / 11$ moment, including preventive policing, risk governance, nuclear strategy, intelligence practices, and biometric technology developments, to name a few. Rather than reading the present as "new" it seems more adequate to read it as mutating various histories through which the contemporary is taking on distinct forms and through which possibilities for future actualizations emerge. "Pre-emptive security" is then the term that names the "milieu" upon which these lines of mutation act.

Equally important for fracturing is the deconstruction of time by multiplying histories. Reading time as becoming challenges singular temporalities. It also disrupts conceptions of time that juxtapose historical time and phenomenological time or that layer longue durée and shorter 
lived times. In these latter conceptions, temporal multiplicities are reduced to variations or manifestations of the longue durée or instances that shape it. In either case, the multiple temporalities of life are reconstructed into continuities that unify the past, present and future into a single history.

Fracturing time deconstructs "reconstructions" of histories that juxtapose historical time and phenomenological time or that layer longue durée and lived times. It introduces minor histories that exist in lived time but also as forgotten, subjugated, or imagined events, moments, knowledges that one (re-)inscribes into the present. At issue is not "recovering" forgotten or subjugated histories as such but rather interfering in contemporary debates by connecting multiple lived times in unexpected ways without unifying them in an alternative global or universal history - that is a grand temporality. Its aim is to interfere in the present in ways that de-familiarize the past and futures and unsettle institutionalized continuities and world histories. Such an understanding of temporality also unsettles conceptions that take the future as the realization of potentialities already inscribed in these institutionalized histories. Becoming makes time precarious; it creates uncertainty about the future, the past and present and in doing so inserts the possibilities for creativity, not necessarily as an intentional action but as immanent to lived lives and worlds.

Methodologically there are various ways of making time precarious. Let's briefly introduce two (but see also Kessler 2012). Michael Shapiro, drawing on Deleuze, Foucault and Ricoeur, fractures time by studying "events of encounters" in narrative genres and filmographic landscapes (Shapiro 2016, 14ff.). For him, these genres have a particular capacity to create events that bring multiple lived times narratively into conversation using visual juxtaposition and association. For example, he unpacks a cinematographic deconstruction of instituted narratives 
and silences of the battle of Okinawa, as performed by a character in the film Level Five who googles for information about the battle (Shapiro 2016, 26ff.). Elsewhere he draws on a novel by Carlos Fuentes who describes a fictional encounter with a local peasant (campesino) in a Mexican village, saying the village's name differs in times of war and times of peace (Shapiro 2016, 15-16). Such "events of encounter" disrupt the idea of a community of time in which "we" all participate. They deconstruct the stability of time instituted through official histories and textbooks among others, thus effecting an openness or precariousness of temporal positioning and possibilities.

Narrative genres are not limited to fiction, however. Heather Johnson's contribution in this issue turns to a narrative genre-stories told by immigrants about their journeys and lived lives - in an attempt to connect everyday time and temporalities of global governance. Her piece is an attempt to collapse the standard method of treating local and global as distinct spatial scales by exploring the encounter between "local" and "global" temporalities as they take shape in the narration of events. The critical issue here is to read the narrative as the simultaneous enactment of global and local times in the narration itself rather than as a window upon, or representation of, two scales that exist outside of the narrative. The effecting of co-existence of multiple times that fractures the practices of stabilizing the organization of time through spatializing it into distinct scales is performed in, and through, the narratives of both the migrants and the analyst who assembles them. Debbie Lisle, in her contribution, also calls for including rhythms of everyday life into the study of international politics. She speaks of it as a method of un-working time to critique the institution of both "instantaneous time" in biometric data and other datafied governmental practices and the perpetual reiteration of crises. 
A different method of fracturing time draws on reading Foucault's method in Discipline and Punish (1975) as the construction of diagrams (Deleuze 1986; Rajchman 1999). The panoptical prison introduces a distinct mode of power-disciplinary power-that shows how different institutions like factories, military, asylums are organized similarly to prisons. It also disrupts the instituted history of sovereign power by inserting a disciplinary history in it. The disruption that the panoptical diagram introduces, however, is not established by merely connecting two different histories but rather by making it possible to see that both discipline and sovereignty are unable to shape the present; both are in crisis and nevertheless at work in the present. It is in this sense that the diagram is a method of making time precarious. "This is not because it makes it possible for us to paint a picture of our distinctive traits and to sketch in advance what we will look like in the future. But it deprives us of our continuities; it dissolves this temporal identity in which we like to look at ourselves" (Foucault, quoted in Deleuze 1992, $165)$.

Reading "discipline" as diagram is quite different from how Foucault's work has been increasingly used in IPS and IR more generally. In IPS, discipline and governmentality are often treated as historical phases or as historical forms that exist in distinct situations or moments. In other words, one separates them by locating them either in distinct institutions and spaces or in distinct historical times. That is quite different from reading panopticon-and other interferences like the genealogy of pastoral power and biopolitical population administration—as diagrams that express situations in which these forms of power co-exist but also bring to light their inability to shape present and futures. If the diagram interferes by making it visible that the present cannot be understood as discrete articulations of one or each of these histories, but as a muddle in which they are all connected but without being able to work in terms of their own 
rationale, then the present is unfixed and precarious in the sense that "we" do not know what to do, that we know something different is going on but we cannot lay our finger on it at the moment. We are not introducing this reading of Foucault's work to say that one cannot read discipline and governmentality as distinct histories and discrete paradigms of power. Of course one can. Yet, to read them as diagrams, as Deleuze (1986), and Rajcham (1999) drawing on him, propose, introduces a method of making time precarious, of fracturing time, of thinking of change and futures as becoming.

In this issue, Bigo, introducing the concept and history of "guilds," can be read as making a diagrammatic intervention. To be clear, that is not what he explicitly articulates in his contribution but neither is it a skewed reading of the work that the histories of "guilds" is doing. Although he formulates it as an intervention in Bourdieuan sociology, his notion of "guilds" can be used to interfere more broadly in unsettling oscillations and/or dialectics between centrifugal and centripetal organizations of power. The exact shape of what is happening in surveillance practices today is not necessarily clear, but it is clear that centripetal histories of statist worlds and professional fields are disrupted in this encounter with "the guild." Yet, it is far from clear that surveillance has gone centrifugal in its organization. It remains linked to centripetal forces of intelligence communities, states, international organizations (Bauman et al. 2014, 124). If we read "the guild" in this context, it is not simply a historical reality, an analogy or a concept but a diagrammatic interference that demonstrates a present that is "out of joint." It indicates the limits of centripetal histories of security politics but also that we cannot solve the coexistence of fields and guilds by locating them simply as two distinct entities or as an expression of a dialectic history driven by contradictions between centrifugal and centripetal organizations of power, classically expressed as a constitutive contradiction between a history of flows and a history of 
sovereignty. The present is disjointed, not because it is split between centrifugal and centripetal practices but rather because alternating between them does not really express what is going on. That is why, in diagrammatic reasoning, the issue is not simply to study guilds but to use guilds to fracture time by connecting histories to think through a present in which both histories are in crisis, thus making it difficult to clearly read the future from the potentialities inscribed in each of them.

Although this take on IPS shares with historical sociology the importance of the study of time (Hobson 2002), it differs from historical sociology. Diagrammatic work and events-inencounter make time much more precarious or fragile than in historical sociologies. The latter remain much more focused on the deeply structured and structuring nature of history, irrespective of whether they seek to read continuities in the world system or transformations of one system into another. The fracturing of time creates a far more future oriented approach than historical sociology in the sense that it does not seek to explain the past so as to know how to go on in the future (for example, so as to avoid unwanted futures). Instead it seeks to understand the actualizations that are taking place today but upon which "we" cannot really lay our hands. Fracturing time thus inscribes the creativity of life and things, creativity not as construction $e x$ nihilo but as little lines of mutation that connect pasts, presents and futures in singular and unsettling ways.

\section{Conclusion}

Instead of simply looking backwards, we decided to celebrate ten years of the journal by contributing in a forward looking way to the ongoing debates about what IPS is and can be. The 
collection of articles in this tenth anniversary issue present between them a selection of themes and modes of doing IPS that have been central to the journal. Yet, each of them also engage a broader theme that has been central to IPS and that we named the fracturing of IR. Fracturing combines the politics of boundary drawing, the importance of lives and repertoires of relating that take place within boundary zones rather than simply between the units on each side of the boundary for understanding transversal relationality and its theoretical, methodological and political stakes today. Practices of separating, discrimination and exclusion remain central points of interest for IPS. However, fracturing also draws our attention to transversal practices and conceptions of relating that challenge, skew, crack or ignore instituted repertoires of knowledge and that configure lived lives in distinct ways that cannot be recaptured as expressions of a world historical or universal structural narrative. In other words, fracturing does not simply reiterate a critical disposition towards exclusions and line drawing and their conditions of possibility and reproduction but also foregrounds an interest in connecting and becoming.

The broader agenda for fracturing IR that we introduced does not fit all that is going on under the heading "IPS," as we experienced during five years of editing the journal. In other words, and not surprisingly, the research that has been published in the journal covers a broader set of lineages and themes than we include in "fracturing." Our introduction, therefore, is intended to be a distinct interference in ongoing debates on what is being and can be practiced under the label "IPS," rather than a statement about "the one and only IPS" possible. In particular, fracturing IR inscribes IPS in two interconnected lineages: a lineage of critique focused on the question of limits and a post-structural lineage, which refers to how to deal with the limits of structuralism while retaining a focus on the conditions of possibility of practice and relations. In doing so, we seek to foreground the problems of structuralism and various post- 
structural engagements with it as a defining and productive lineage for taking IPS forward. It is an agenda for contributions to IPS that experiment theoretically, conceptually and methodologically with connecting and becoming to re-inscribe the "post" of structuralism and to reinvent the question of limits in ways that speak to the contemporary in IR and world politics.

References

Abrahamsen, Rita, And Michael C. Williams. 2009. "Security Beyond the State: Global Security Assemblages in International Politics." International Political Sociology 3 (1): $1-17$.

Agnew, John A. 2009. Globalization and Sovereignty. Lanham: Rowman \& Littlefield.

ALBert, Mathias. 2007. "'Globalization Theory': Yesterday's Fad or More Lively than Ever?" International Political Sociology 1 (2): 165-182.

Althusser, Louis, François Matheron, AND Olivier Corpet. 2006. Philosophy of the encounter : later writings, 1978-87. London; New York: Verso

Amoore, Louise. 2013. The Politics of Possibility. Risk and Security Beyond Probability. Durham: Duke University Press.

Amoore, Louise, AND MARIEKe De Goede. 2008. Risk and the War on Terror. London: Routledge.

Andrijasevic, Rutvica. 2010. Migration, Agency and Citizenship in Sex Trafficking. Basingstoke: Palgrave Macmillan.

Andrijasevic, Rutvica, Aradau, Claudia, Huysmans, Jef \& Squire, Vicki. 2012. "European citizenship unbound: Sex work, mobility, mobilisation." Environment and Planning D: Society and Space 30(3): 497-514.

Ansems De VRIES, LeONIE. 2015. Re-Imagining a Politics of Life. From Governance of Order to Politics of Movement. London: Rowman \& Littlefield.

Aradau, Claudia, Jef Huysmans, and Vicki SQuire. 2010. "Acts of European Citizenship: A Political Sociology of Mobility.” Journal of Common Market Studies 48 (4): 945-965.

Aradau, Claudia, And Rens van Munster. 2008. "Taming the Future: The Dispositif of Risk in the War on Terror." In Risk and the War on Terror, edited by Louise Amoore and Marieke De Goede, 23-40. London: Routledge.

Ashley, RichaRD. 1984. "The Poverty of Neorealism." International Organization 38 (2): 225 286.

Ashley, RicharD. 1987. "The Geopolitics of Geopolitical Space. Toward a Critical Social Theory of International Politics." Alternatives 12 (4): 403-434.

Austin, Jonathan LuKe. 2016. "Torture and the Material-Semiotic Networks of Violence across Borders." International Political Sociology 10 (1): 3-21.

Barabantseva, Elena. 2015. "When Borders Lie Within: Ethnic Marriages and Illegality on the Sino-Vietnamese Border.” International Political Sociology 9 (4): 352-368. 
Barnett, Michael N., And Martha Finnemore. 2004. Rules For the World: International Organizations in Global Politics. Ithaca, N.Y.: Cornell University Press.

BARry, ANDrEW, AND GEORGINA Borne. 2013. Interdisciplinarity: Reconfigurations of the Social and Natural Sciences. Abingdon: Routledge.

Bartelson, Jens. 2010. "The Social Construction of Globality." International Political Sociology 4 (3): 219-235.

Bartelson, Jens. 2014. Sovereignty as Symbolic Form. Critical Issues in Global Politics. London: Routledge.

BARTElson, Jens. 2015. "Towards a Genealogy of "Society' in International Relations." Review of International Studies, FirstView: 1-18. Basaran, Tugba, Didier Bigo, EMmanuelPierre Guittet, And R.B.J. Walker, Eds. 2016. International Political Sociology. Transversal Lines. Abingdon: Routledge.

Bauman, Zygmunt, Didier Bigo, Paulo Esteves, Elspeth Guild, Vivienne Jabri, David LYON, AND R.B.J. WALKER. 2014. "After Snowden: Rethinking the Impact of Surveillance.” International Political Sociology 8 (2): 121-144.

Bayart, Jean-François, Achille Mbembe, and Comi Toulabor. 2008. Le Politique Par Le Bas En Afrique Noire. Paris: Karthala.

Bellanova, Rocco, And Gloria GonzÁlez Fuster. 2013. "Politics of Disappearance: Scanners and (Unobserved) Bodies as Mediators of Security Practices." International Political Sociology 7 (2): 188-209.

Best, JACQUELINE. 2008. "Ambiguity, Uncertainty, and Risk: Rethinking Indeterminacy." International Political Sociology 2 (4): 355-374.

Best, JaCQueline, AND William Walters. 2013. "Translating the Sociology of Translation." International Political Sociology 7 (3): 345-349.

Bhambra, Gurminder K. 2014. Connected Sociologies. London: Bloomsbury.

Bigo, Didier. 2011. "Pierre Bourdieu and International Relations: Power of Practices, Practices of Power." International Political Sociology 5 (3): 225-258.

Bigo, Didier, And Mikael R. Madsen. 2011. "Introduction to Symposium. "A Different Reading of the International": Pierre Bourdieu and International Studies." International Political Sociology 5 (3): 219-224.

Bigo, Didier, AND R.B.J. WALKer. 2007a. "International, Political, Sociology." International Political Sociology 1 (1): 1-5.

Bigo, Didier, AND R.B.J. WALKer. 2007b. "Political Sociology and the Problem of the International." Millennium-Journal of International Studies 35 (3): 725-739.

Bigo, DidiER. 2016. "International Political Sociology: Rethinking the International Through Dynamics of Power." In International Political Sociology: Transversal Lines, edited by Didier Bigo, R.B.J. Walker, Emmanuel-Pierre Guittet and Tugba Basaran, 24-48. Abingdon: Routledge.

Bleiker, Roland. 2000. Popular Dissent, Human Agency and Global Politics. Cambridge: Cambridge University Press.

Budz, Michele. 2009. “A Heterotopian Analysis of Maritime Refugee Incidents.” International Political Sociology 3 (1): 18-35.

Chauvin, SÉbastien, And Blanca Garcés-Mascareñas. 2012. "Beyond Informal Citizenship: The New Moral Economy of Migrant Illegality." International Political Sociology 6 (3): 241-259. 
Chote, Simon. 2010. Marx through Post-Structuralism: Lyotard, Derrida, Foucault, Deleuze. London: Continuum.

Cohen, Antonin. 2010. "Legal Professionals or Political Entrepreneurs? Constitution Making as a Process of Social Construction and Political Mobilization." International Political Sociology 4 (2): 107-123.

Collier, Stephen J., AND Ainwa Ong. 2005. "Global Assemblages, Anthropological Problems." In Global Assemblages. Technology, Politics and Ethics as Anthropological Problems, edited by Stephen J. Collier and Aihwa Ong, 3-21. Oxford: Blackwell Publishing.

Cox, Robert W., And Timothy J. Sinclair. 1996. Approaches to World Order. Cambridge: Cambridge University Press.

D'Aoust, Anne-Marie. 2013. "In the Name of Love: Marriage Migration, Governmentality, and Technologies of Love." International Political Sociology 7 (3): 258-274.

Davies, Matt. 2016. "Everyday Life as Critique: Revisiting the Everyday in Ipe with Henri Lefebvre and Postcolonialism.” International Political Sociology 10 (1): 22-38.

De Goede, Marieke. 2012. Speculative Security. The Politics of Pursuing Terrorist Monies. Minneapolis: University of Minnesota Press.

DE Goede, MARIEKE. 2016. "Afterword: Transversal Politics." In Routledge Handbook of International Political Sociology, edited by Xavier Guillaume and Pinar Bilgin. Abingdon: Routledge.

Deleuze, GiLles. 1979. "Foreword. The Rise of the Social." In The Policing of Families, edited by Jacques Donzelot, ix-Xvii. New York: Pantheon Books.

Deleuze, GiLles. 1986. Foucault. Paris: Les éditions de minuit.

Deleuze, Gilles. 1992. "What Is a Dispositifs?" In Michel Foucault. Philosopher, edited by Michel Foucault, 159-168. Hemel Hempstead: Harvester Wheatsheaf.

Der Derian, JAMES, AND Michael ShapiRo. 1989. International/Intertextual Relations. Postmodern Readings of World Politics. Lexington: Lexington Books.

Dezalay, Yves, And Bryant G. Garth. 2011. "Hegemonic Battles, Professional Rivalries, and the International Division of Labor in the Market for the Import and Export of StateGoverning Expertise.” International Political Sociology 5 (3): 276-293.

Dunn CAVelty, Myriam, And Mark Daniel JAEGER. 2015. "(in)Visible Ghosts in the Machine and the Powers That Bind: The Relational Securitization of Anonymous." International Political Sociology 9 (2): 176-194.

Enloe, Cynthia. 1989. Bananas, Beaches and Bases. Making Feminist Sense of International Relations. London: Pandora.

FoucAult, Michel. 1975. Surveiller Et Punir. Naissance De La Prison. Paris: Gallimard.

FOUCAUlt, Michel. 2002. The Order of Things. London: Routledge.

GiLl, StePhen, ed. 1993. Gramsci, Historical Materialism and International Relations. Cambridge: Cambridge University Press.

Gill, StePhen. 2003. Power and Resistance in the New World Order. New York: Palgrave Macmillan.

Grosz, ElizaBeth. 1999. "Becoming ... An Introduction.” In Becomings. Explorations in Time, Memory and Futures, edited by Elizabeth Grosz, 1-12. New York: Cornell University Press.

Guillaume, XaVier. 2009. "From Process to Politics." International Political Sociology 3 (1): 71-86. 
Guillaume, XaVier. 2007. "Unveiling the 'International': Process, Identity and Alterity." Millennium: Journal of International Studies 35 (3): 741-759.

Guillaume, Xavier, And Pinar Bilgin. 2016. "Introduction to the Routledge Handbook of International Political Sociology." In Routledge Handbook of International Political Sociology, edited by Xavier Guillaume and Pinar Bilgin. Abingdon: Routledge.

Guzzini, Stefano. 2016. "International Political Sociology, Or: The Social Ontology and Power Politics of Process." In Routledge Handbook of International Political Sociology, edited by Xavier Guillaume and Pinar Bilgin. Abingdon: Routledge.

Hindess, BARRY. 2005. "Politics as Government: Michel Foucault's Analysis of Political Reason." Alternatives: Global, Local, Political 30 (4): 389-413.

HoBSON, JOHN M. 2002. "What's at Stake in 'Bringing Historical Sociology Back into International Relations? Transcending 'Chronofetishism' and 'Tempocentrism' in International Relations." In Historical Sociology of International Relations, edited by Stephen Hobden and John M. Hobson, 3-41. Cambridge: Cambridge University Press.

Hutchings, Kimberly. 2008. Time and World Politics: Thinking the Present. Manchester: Manchester University Press.

Huysmans, JeF, AND XaVIER GuIllaume. 2013. "Citizenship and Securitizing: Interstitial Politics." In Citizenship and Security. The Constitution of Political Being, edited by Xavier Guillaume and Jef Huysmans, 18-34. Abingdon: Routledge.

Huysmans, Jef, Anna Leander, Jens Bartelson, George M. Thomas, Roland Robertson, Barry Hindess, Mathias Albert, Hans-Martin Jaeger, AND Oliver Kessler. 2009. "IPS Forum on Global Society." International Political Sociology 3 (1): 109-136.

IsIn, ENGIN F., AND GREG M. NIELSEN. 2008. Acts of Citizenship. London: Zed Books.

Isin, Engin F., And Evelyn Ruppert. 2015. Being Digital Citizens. London: Rowman \& Littlefield.

Jackson, Patrick Thaddeus, And Daniel H. Nexon. 1999. "Relations before States: Substance, Process and the Study of World Politics." European Journal of International Relations 5 (3): 291-332.

Katzenstein, Peter J., Robert O. Keohane, And Stephen Krasner. 1998. "International Organization and the Study of World Politics." International Organization 52 (4): 645685.

Keohane, Robert O. 2002. Power and Governance in a Partially Globalized World. London: Routledge.

Keohane, Robert O., And Joseph Nye. 1977. Power and Interdependence. Boston: Little, Brown and Company.

KeSSLER, Oliver. 2009. "Toward a Sociology of the International? International Relations between Anarchy and World Society." International Political Sociology 3 (1): 87-108.

Kessler, Oliver. 2012. "World Society, Social Differentiation and Time." International Political Sociology 6 (1): 77-94.

KopPeR, Ákos. 2012. "The Imaginary of Borders: From a Coloring Book to Cézanne's Paintings." International Political Sociology 6 (3): 277-293.

Kratochwil, Friedrich V. 1989. Rules, Norms, and Decisions: On the Conditions of Practical and Legal Reasoning in International Relations and Domestic Affairs. Cambridge: Cambridge University Press. 
KurKi, Milja. 2011. "Governmentality and EU Democracy Promotion: The European Instrument for Democracy and Human Rights and the Construction of Democratic Civil Societies." International Political Sociology 5 (4): 349-366.

LeAnder, AnNA. 2011. "The Promises, Problems, and Potentials of a Bourdieu-Inspired Staging of International Relations." International Political Sociology 5 (3): 294-313.

LEANDER, ANNA. 2016. "Afterword: The Commercial in/for International Political Sociology." In Routledge Handbook of International Political Sociology, edited by Xavier Guillaume and Pinar Bilgin. Abingdon: Routledge.

Linklater, ANDREW. 1998. The Transformation of Political Community: Ethical Foundations of the Post-Westphalian Era. Columbia: University of South Carolina Press.

Macherey, Pierre. 2009. Petits Riens: Ornières Et Dérives Du Quotidien. Lormont: Editions Le Bord de l'eau.

Marston, Sallie A., John Paul Jones III, And Keith Woodward. 2005. "Human Geography without Scale." Transactions of the Institute of British Geographers 30 (4): 416-432.

Ní Mhurchú, AoILeann. 2015. "Ambiguous Subjectivity, Irregular Citizenship: From Inside/Outside to Being-Caught In-between." International Political Sociology 9 (2): 158-175.

Papadopoulos, Dimitris, Niamh Stephenson, And Vassilis Tsianos. 2008. Escape Routes. Control and Subversion in the 21st Century. London: Pluto Press.

Rabinow, PaUl. 2003. Anthropos Today. Reflections on Modern Equipment. Princeton: Princeton University Press.

Rabinow, Paul. 2008. Marking Time. On the Anthropology of the Contemporary. Princeton: Princeton University Press.

Rajchman, John. 1999. "Diagram and Diagnosis." In Becomings. Explorations in Time, Memory, and Futures, edited by Elizabeth Grosz, 42-54. New York: Cornell University Press.

Ryan, CAitlin. 2015. "Everyday Resilience as Resistance: Palestinian Women Practicing Sumud.” International Political Sociology 9 (4): 299-315.

Ruggie, John Gerard. 1993. "Territoriality and Beyond: Problematizing Modernity in International Relations." International Organization 47 (1): 139-174.

Sassen, Saskia. 2006. Territory, Authority, Rights. From Medieval to Global Assemblages. Princeton: Princeton University Press.

Scheel, Stephan. 2013. "Studying Embodied Encounters: Autonomy of Migration Beyond Its Romanticization." Postcolonial Studies 16 (3): 279-288.

Schouten, PeER. 2014. "Security as Controversy: Reassembling Security at Amsterdam Airport." Security Dialogue 45 (1): 23-42.

SETH, SANJAY. 2013. “"'Once Was Blind but Now Can See”: Modernity and the Social Sciences." International Political Sociology 7 (2): 136-151.

Shapiro, Michael. 2016. Politics and Time. Cambridge: Polity.

Shilliam, RoBbie. 2015. The Black Pacific. Anti-Colonial Struggles and Oceanic Connections. London: Bloomsbury.

SHINDO, REIKO. 2012. "Rethinking Community: Translation Space as a Departure from Political Community." International Political Sociology 6 (2): 149-164.

Simmel, Georg. 1971. "The Problem of Sociology." In Georg Simmel on Individuality and Social Forms, edited by Donald N. Levine, 23-35. Chicago: The University of Chicago Press. 
Slaughter, Anne-Marie. 2005. A New World Order. Princeton: Princeton University Press.

SOREANU, RALUCA. 2010. "Feminist Creativities and the Disciplinary Imaginary of International Relations." International Political Sociology 4 (4): 380-400.

SQuire, VICKI. 2011. "The Contested Politics of Mobility. Borderzones and Irregularity." Abingdon: Routledge.

Squire, Vicki, And Jonathan Darling. 2013. "The "Minor" Politics of Rightful Presence: Justice and Relationality in City of Sanctuary." International Political Sociology 7 (1): 59-74.

Strange, Susan. 1996. The Retreat of the State. The Diffusion of Power in the World Economy. Cambridge: Cambridge University Press.

Sylvester, Christine. 1994. Feminist Theory and International Relations in a Postmodern Era. Cambridge: Cambridge University Press.

Thomas, George M. 2009. "World Polity, World Culture, World Society." International Political Sociology 3 (1): 115-119.

TOSA, HiROYUKI. 2009. "Anarchical Governance: Neoliberal Governmentality in Resonance with the State of Exception." International Political Sociology 3 (4): 414-430.

Vaughan-Williams, Nick. 2008. Borders, Territory, Law. International Political Sociology 2 (4): 322-338.

Villumsen Berling, Trine. 2015. The International Political Sociology of Security. Rethinking Theory and Practice. Abingdon: Routledge.

WÆVER, OLE. 1997. "Figures of International Thought: Introducing Persons Instead of Paradigms." In The Future of International Relations. Masters in the Making, edited by Iver B. Neumann and Ole Wæver, 1-37. London: Routledge.

Walker, R.B.J. 1993. Inside/Outside: International Relations as Political Theory. Cambridge: Cambridge University Press.

WALKer, R.B.J. 1995. "From International Relations to World Politics." In The State in Transition: Reimagining Political Space, edited by Joseph A. Camilleri, Anthony P. Jarvis and Albert J. Paolini, 21-38. Boulder: Lynne Rienner.

WALKer, R.B.J. 2010. After the Globe, Before the World. Abingdon: Routledge.

Weber, Cynthia. 2010. "Citizenship, Security, Humanity.” International Political Sociology 4 (1): 80-85.

Weldes, Jutta, Mark Laffey, Hugh Gusterson, and Raymond Duvall. 1999. Cultures of Insecurity. States, Communities, and the Production of Danger. Minneapolis: University of Minnesota Press.

Wendt, Alexander. 1999. Social Theory of International Politics. Cambridge: Cambridge University Press. 